\title{
Genetic diversity of the E Protein of Dengue Type 3 Virus
} Alberto A Amarilla ${ }^{1}$, Flavia T de Almeida ${ }^{2}$, Daniel M Jorge ${ }^{3}$, Helda L Alfonso ${ }^{1}$, Luiza A de Castro-Jorge ${ }^{1}$, Nadia A Nogueira ${ }^{4}$, Luiz T Figueiredo ${ }^{1}$ and Victor H Aquino*2

Address: ${ }^{1}$ Virology Research Center, School of Medicine of Ribeirão Preto/USP, Ribeirão Preto - SP, Brazil, ${ }^{2}$ Department of Clinical, Toxicological and Bromatological Analysis, FCFRP/USP, Ribeirão Preto - SP, Brazil, ${ }^{3}$ Bioinformatics Laboratory, Department of Genetics, School of Medicine of Ribeirão Preto/USP, Ribeirão Preto - SP, Brazil and ${ }^{4}$ Department of Toxicological and Clinical Analysis, Federal University of Ceara, Brazil

Email: Alberto A Amarilla - alberilla@yahoo.com.ar; Flavia T de Almeida - flavia_tche@yahoo.com.br;

Daniel M Jorge - danielmacedo.jorge@gmail.com; Helda L Alfonso - alfonso_helda@yahoo.com.ar; Luiza A de Castro-

Jorge - luizacastro@gmail.com; Nadia A Nogueira - acciolyufc@gmail.com; Luiz T Figueiredo - ltmfigue@fmrp.usp.br;

Victor H Aquino* - vhugo@fcfrp.usp.br

* Corresponding author

Published: 23 July 2009

Virology Journal 2009, 6:1 I3 doi:I0.1186/1743-422X-6-113

This article is available from: http://www.virologyj.com/content/6/I/II3

(c) 2009 Amarilla et al; licensee BioMed Central Ltd.

This is an Open Access article distributed under the terms of the Creative Commons Attribution License (http://creativecommons.org/licenses/by/2.0), which permits unrestricted use, distribution, and reproduction in any medium, provided the original work is properly cited.

\begin{abstract}
Background: Dengue is the most important arbovirus disease in tropical and subtropical countries. The viral envelope (E) protein is responsible for cell receptor binding and is the main target of neutralizing antibodies. The aim of this study was to analyze the diversity of the $E$ protein gene of DENV-3. E protein gene sequences of 20 new viruses isolated in Ribeirao Preto, Brazil, and 427 sequences retrieved from GenBank were aligned for diversity and phylogenetic analysis.
\end{abstract}

Results: Comparison of the $E$ protein gene sequences revealed the presence of 47 variable sites distributed in the protein; most of those amino acids changes are located on the viral surface. The phylogenetic analysis showed the distribution of DENV-3 in four genotypes. Genotypes I, II and III revealed internal groups that we have called lineages and sub-lineages. All amino acids that characterize a group (genotype, lineage, or sub-lineage) are located in the 47 variable sites of the $E$ protein.

Conclusion: Our results provide information about the most frequent amino acid changes and diversity of the E protein of DENV-3.

\section{Background}

During the first decades of the $20^{\text {th }}$ century, dengue was considered a sporadic disease, causing epidemics at long intervals. However, dramatic changes in this pattern have occurred and, currently, dengue is the most important mosquito-borne viral disease worldwide. Approximately, 3 billion people are at risk of acquiring dengue viral infections in more than 100 countries in tropical and subtropical regions. Annually, it is estimated that 100 million cases of DF and half a million cases of dengue DHF/DSS occur worldwide resulting in approximately 25,000 deaths [1]. Dengue disease can be caused by any of the four antigenically related viruses named dengue virus type $1,2,3$ and 4 (DENV-1, -2, -3 and -4). All of these serotypes can cause a large spectrum of clinical presentations, ranging from asymptomatic infection to dengue fever (DF) and to the most severe form, dengue haemorrhagic fever/ dengue shock syndrome (DHF/DSS). Early diagnosis of 
dengue virus infection, which can be achieved by detecting a viral protein or genome, is important for patient management and control of dengue outbreaks [2].

Dengue is an enveloped virus with a single-stranded, positive-sense RNA genome of about $11 \mathrm{~kb}$ containing a single open reading frame, flanked by untranslated regions (5' and 3' UTR) [3]. The viral RNA encodes a single polyprotein, which is co- and pos-translationally cleaved into 3 structural (C, prM and $\mathrm{E}$ ) and 7 nonstructural proteins (NS1-NS2A-NS2B-NS3-NS4A-NS4B-NS5) proteins [4]. The envelope (E) glycoprotein is the major component of the virion external surface, responsible for important phenotypic and immunogenic properties. E protein is a multifunctional protein, which is involved in cell receptor binding and virus entry via fusion with host cell membranes. Thus, E protein is the main target of neutralizing antibodies [5-10]. The crystal structure analysis of this protein revealed that it includes three domains (I, II, and III) that exhibit significant structural conservation when compared to other flaviviruses [11]. For flaviviruses, most of amino acid residues related to host range determinant, tropism and virulence are located in domain III $[12,13]$.

Similar to other RNA viruses, DENV exhibit a high degree of genetic variation due to the non-proofreading activity of the viral RNA polymerase, rapid rates of replication, immense population size, and immunological pressure [14]. Historically, variants within each DENV serotype have been classified in different ways, accompanying technological progress. Studies from the seventies showed the existence of antigenic variants within DENV-3 showing that DENV-3 strains from Puerto Rico and Tahiti were antigenically and biologically different from those of Asia [15]. In the eighties, the term "topotype", based on RNA fingerprinting, was used to define five genetic variants within DENV-2 [16,17]. Other molecular methods such as cDNA-RNA hybridization, hybridization using synthetic oligonucleotides, and restriction endonuclease analysis of RT-PCR products were also used to demonstrate the existence of genetic variability within each serotype [18-22]. In the nineties, the use of nucleic acid sequencing methods and phylogenetic analysis allowed the identification of different genomic groups, called "genotypes" or "subtypes", within each DENV serotype [23-25]. Today, several geographically distinct genotypes are described within each serotype. Thus, DENV-1 includes five genotypes: genotype I contains viruses from the Americas, Africa, and Southeast Asia; genotype II includes a single isolate from Sri Lanka; genotype III includes a strain from Japan isolated in 1943; genotype IV includes strains from Southeast Asia, the South Pacific, Australia, and Mexico; and genotype $\mathrm{V}$ group contains viruses from Taiwan and Thailand [23,26,27]. DENV-2 encompasses six genotypes denominated Asian I, Asian II,
American, American/Asian, Cosmopolitan and Sylvatic $[23,24,28]$. DENV-3 was classified into four genotypes: genotype I comprises viruses from Indonesia, Malaysia, Philippines and the South Pacific islands; genotype II comprises viruses from Thailand; genotype III is represented by viruses from Sri Lanka, India, Africa and America; genotype IV comprises Puerto Rican viruses. Recently, it has been suggested that exist an additional group that was named genotype V $[25,29]$. DENV-4 was classified into two genetically distinct genotypes. Genotype I includes viruses from the Philippines, Thailand and Sri Lanka; genotype II includes viruses from Indonesia, Tahiti, Caribbean Islands (Puerto Rico, Dominica) and Central and South America [30]. A third genotype of DENV-4 was identified which includes sylvatic isolates that formed a distinct genotype [27].

Increased numbers of DENV sequences in the GenBank has given a better picture of the genetic diversity of these viruses, suggesting the existence of intragenotipic groups within each genotype. Identification of these groups will lead to a better understanding of the migration pattern of the viruses, as well as the detection of emergent viruses with altered antigenicity, virulence, or tissue tropism. In this study, we have analyzed the variability of the E protein gene of DENV-3 by comparison of new and GenBank deposited sequences and found several lineage and sublineages within the different genotypes.

\section{Results}

Nucleotide sequences of the E protein gene (1479 bp) of 20 DENV-3 strains isolated in Ribeirao Preto and 427 sequences retrieved from the GenBank were included in this study. These sequences represent viruses isolated between 1956 and 2007. After an initial analysis, 75 identical sequences, three recombinant strains, two mutants, one rare, and five sequences corresponding to the same five strains deposited with different access codes were excluded from the study (Additional file 1) [29,31]. Thus, 361 sequences were used to analyze the E protein diversity and the phylogenetic relationship of the viruses.

To analyze the diversity of the $\mathrm{E}$ protein, nucleotide sequences were aligned and compared. Any of the 1479 sites in the alignment were considered a variable site when at least one virus showed a nucleotide substitution at that site. By this criteria, 634 variable sites were found to be evenly distributed in the E protein gene; 157 of these showed non-synonymous substitutions (substitutions in the codon that induce amino acid changes) (Additional file 2). Seventy non-synonymous substitutions sites were observed only in one virus, 28 sites in two viruses and 59 sites in three or more viruses. 
Based on the aligned nucleotide sequences, several phylogenetic analysis including maximum parsimony and distance methods were performed and all approaches yielded identical or nearly identical topologies. The phylogenetic tree showed four genetic groups within the DENV-3 (Figure 1) where genotype I was represented by strains from Indonesia, Malaysia, Philippines and the South Pacific islands; genotype II included mainly isolates from Thailand; genotype III was represented mainly by viruses from Sri Lanka and Latin America and genotype IV comprised Puerto Rican viruses.

For a better characterization of the genetic groups, E protein gene sequences of all viruses were compared manually. As mentioned above, 634 variable sites were observed within the 1479 nucleotides of the E protein gene (Additional file 2). Variable sites with nucleotide substitutions in at least $90 \%$ of the members of any genotype were considered informative sites. Thus, 95 of the 634 were considered informative sites. Among these 95, 18 sites were in the domain I of E protein, 28 in domain II, 27 in domain III, and 22 in the transmembrane domain (Additional file 3). Each genotype showed a characteristic nucleotide sequence when the informative sites were analyzed. Nucleotide substitution in the informative sites was mostly due to transitions ( 80 sites, $81 \%$ ) rather than transversions (21 sites, 19\%). Nucleotide substitution were more frequent in the 3rd position (74 sites, $78 \%$ ) of the codon, followed by the first position (15 sites, $16 \%$ ) and finally, the second position ( 6 sites, $6 \%$ ). Non-synonymous substitutions were observed in 14 (15\%) of the 95 informative sites (residues 22, 81, 132, $154,160,270,301,302,380,383,386,430,452$ and 459). Three non-synonymous substitutions were identified in domain I, three in domain II, five in domain III, and three in the transmembrane domain (Additional file 3 ). Based on the tertiary structure of the $E$ protein of DENV-3 (36), it was observed that amino acid residues $81,132,154,270,301,302,380$, and 383 were located in solvent-exposed loops. Residues 22 and 386 were located in $\beta$-strands exposed on the viral surface. The residue 160 was located in a hydrophobic region. Residues 430, 452 and 459 were located in the transmembrane region (Additional file 4A).

\section{Intragenotipic groups}

Careful analysis of the topology of the phylogenetic tree suggests the existence of intragenotipic groups (Figure 1). To better characterize these internal groups, protein E gene sequences of members of each genotype were independently analyzed.

\section{Genotype I}

A phylogenetic tree was constructed using 76 protein $\mathrm{E}$ gene sequences of genotype I viruses (Figure 2). The tree showed that these viruses form two different clades that were denominated lineage I and II. The nucleotide sequence comparison showed the presence of 348 variable sites in the 1479 nucleotides of the $\mathrm{E}$ protein gene with 40 of them considered informative sites. Non-synonymous substitutions were observed in seven informative sites (Table 1). Amino acid residues 231, 303 and 391 were found to be located in solvent-exposed loops, residues 68 and 169 in hydrophobic regions (Additional file 4B). Residues 479 and 489 were located in the transmembrane region.

The phylogenetic tree showed that lineage II included two sub-lineages (Figure 2). The comparison of nucleotide sequences $(n=68)$ showed the presence of 318 variable sites within members of this lineage, six of them being informative sites with synonymous substitutions (Table 1).

\section{Genotype II}

Genotype II included 144 viruses that were grouped into two lineages (Figure 3). Comparison of these sequences showed 392 variable sites; four of them being informative sites with synonymous substitutions (Table 2). Lineage I included 62 sequences that form two sub-lineages with 255 variable sites; 17 of them were considered informative sites and three had non-synonymous substitutions (Table 3). The amino acid residue 140 was located in a $\beta$ strand exposed in the surface of the protein; residues 447 and 489 were in the transmembrane domain (Additional file 4C). Lineage II included 83 viruses distributed in two sub-lineages. The comparison of these sequences showed 275 variable sites with only two informative sites, which showed synonymous substitutions (Table 2 ).

\section{Genotype III}

Genotype III was composed of 138 sequences grouped in two lineages (Figure 4). Sequences comparison showed 321 variable sites with 11 informative sites, all of them with synonymous substitutions. Lineage I included 29 sequences grouped into sub-lineage I and II with 123 variable sites with only one of them considered as informative site, which showed a synonymous substitution (Table 3). The lineage II included 108 sequences forming two groups, sub-lineage I and II; these sequences showed 250 variable sites and only seven of them were considered as informative sites, all of them were synonymous substitutions (Table 3). The sub-lineage II of lineage II included the 20 viruses isolated in Ribeirao Preto, SP, Brazil, between 2006-2007. These viruses were more closely related to those isolated in other regions of Brazil than to viruses that circulated in Ribeirao Preto, in 2003 (D3BR/ RP1/2003 and D3BR/RP2/2003). They formed two groups, one more closely related to the strain D3BR/CU6/ 2002 isolated in Cuiabá close to the border with Bolivia 


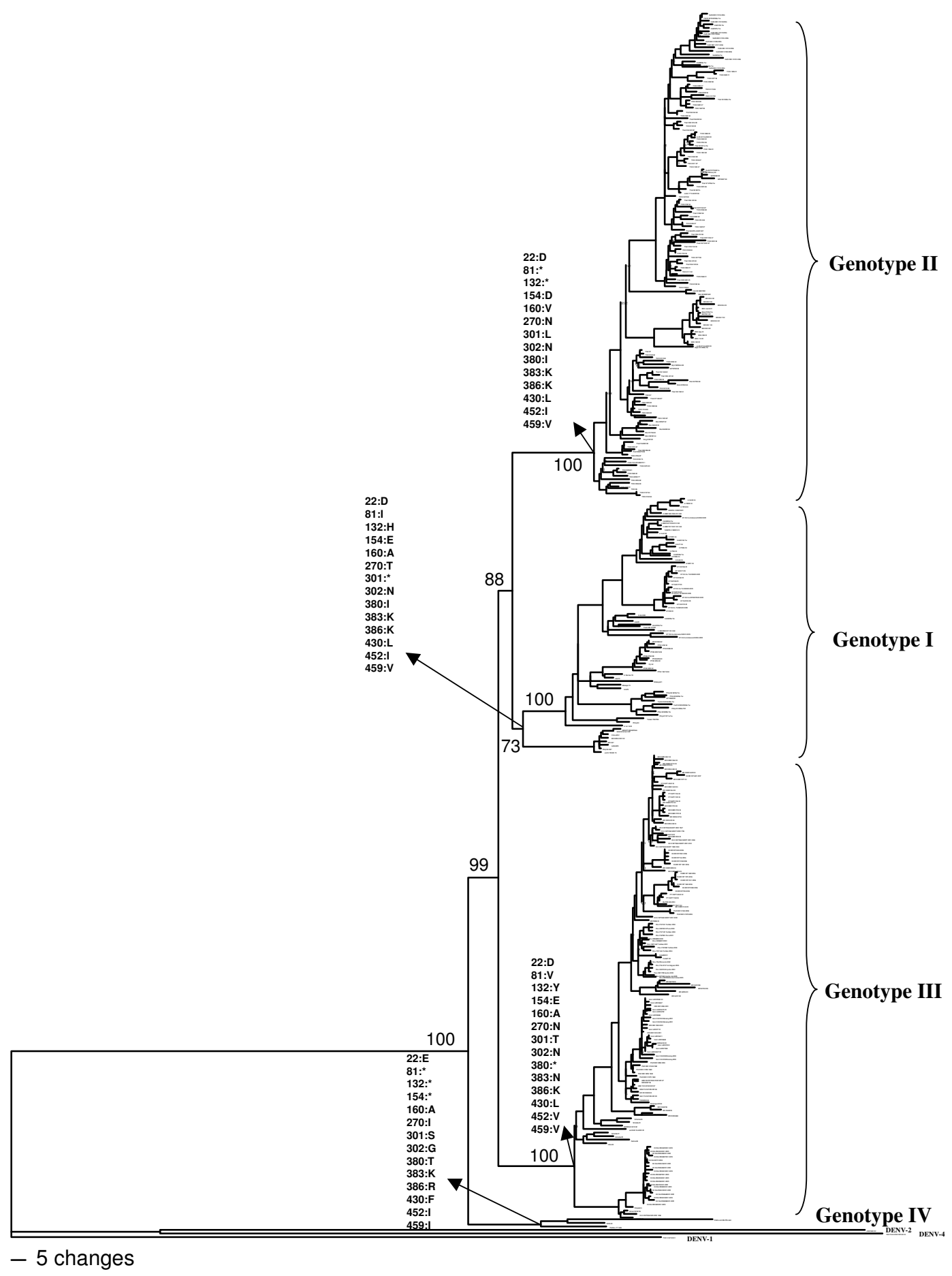

Figure I

DENV-3 phylogenetic tree based on the E gene sequences. The three was constructed using the method of Neighborjoining with 1000 bootstrap replications. The genotypes are labeled according to the scheme of Lanciotti (1994) and the amino acid changes distinguishing each genotype are shown on the tree. Protein E gene sequences of DENV-I, DENV-2 and DENV-4 were used as outgroup. Branch lengths are proportional to percentage of divergence. Tamura Nei $(\operatorname{TrN}+I+G)$ nucleotide substitution model was used with a proportion of invariable sites (I) of 0.3305 and gamma distribution (G) of 0.99 II. Bootstrap support values are shown for key nodes only. 


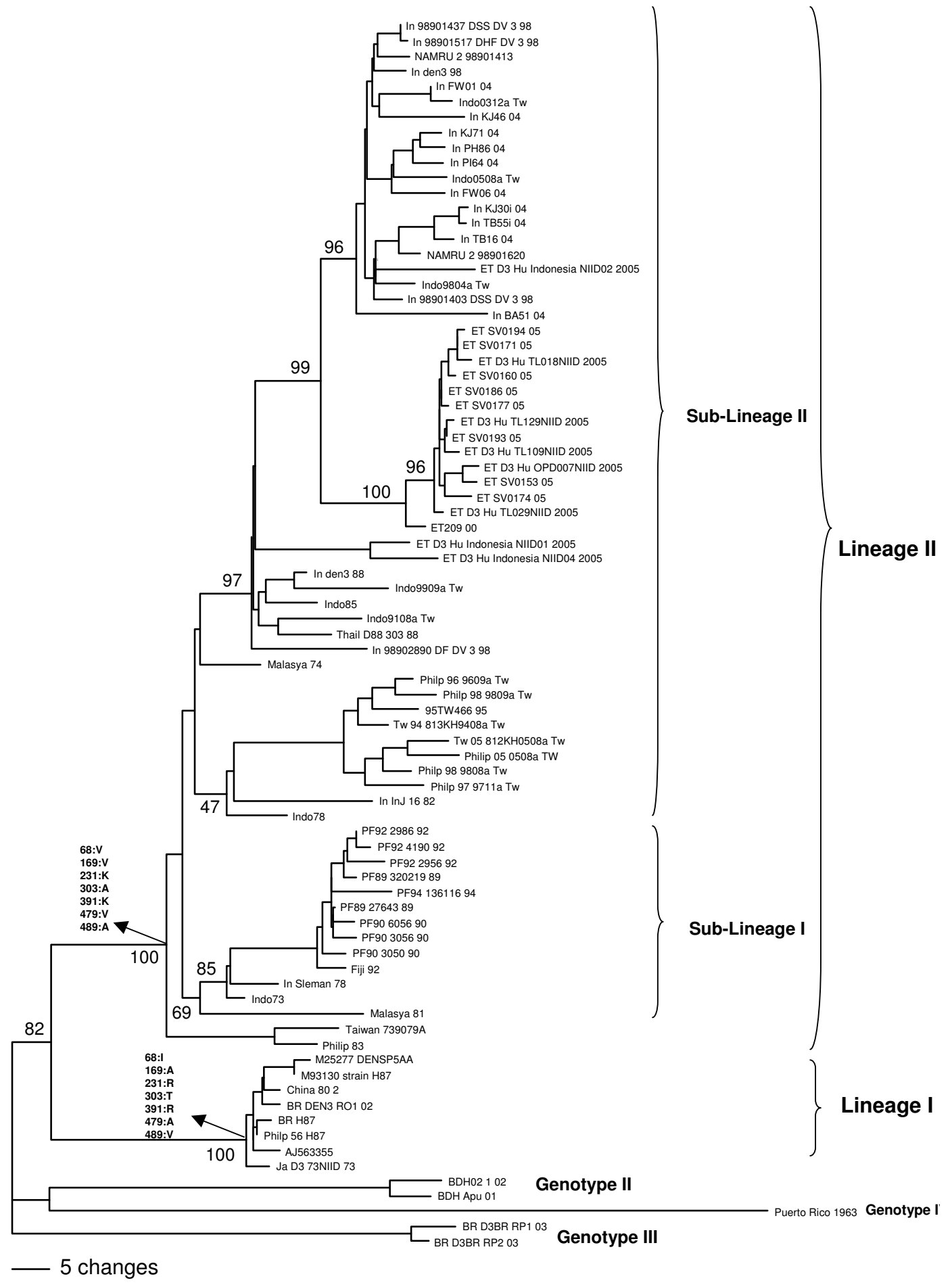

Figure 2

Genotype I phylogenetic tree constructed using the method of Neighbor-joining with 1000 bootstrap replications. Sequences of each genotype II, III and IV were used as outgroup. Branch lengths are proportional to percentage divergence. Tamura Nei $(\mathrm{TrN}+\mathrm{I}+\mathrm{G})$ nucleotide substitution model was used with a proportion of invariable sites (I) of 0.5420 and gamma distribution $(\mathrm{G})$ of 2.6 122 . The lineage and sub-lineages are marked. Amino acids changes are indicated on the tree. Bootstrap support values are shown for key nodes only. 
Table I: Nucleotide and amino acid substitutions in the informative sites of genotype I.

\begin{tabular}{|c|c|c|c|c|c|c|c|c|c|c|}
\hline \multicolumn{6}{|c|}{ Nucleotide } & \multicolumn{4}{|c|}{ Protein } & \multirow[t]{3}{*}{ Domains } \\
\hline & & \multicolumn{4}{|c|}{ Genotype I } & & & & & \\
\hline \multicolumn{2}{|c|}{ Position } & \multicolumn{2}{|c|}{ Lineage } & \multicolumn{2}{|c|}{$\begin{array}{c}\text { Lineage II } \\
\text { Sub-Lineage }\end{array}$} & \multirow{2}{*}{$\begin{array}{l}\text { Position } \\
\text { Protein }\end{array}$} & \multicolumn{2}{|c|}{ Lineagen } & \multirow[t]{2}{*}{ Type of amino acid Changes } & \\
\hline Gene & Codon & $\mathbf{I}$ & II & $\mathbf{I}$ & II & & $\mathbf{I}$ & II & & 1 \\
\hline 48 & 3 & $\mathrm{G}$ & $A$ & & & & & & & \\
\hline 135 & 3 & $\mathrm{~T}$ & $\mathrm{C}$ & & & & & & & \\
\hline 174 & 3 & $\mathrm{G}$ & A & & & & & & & II \\
\hline 202 & 1 & $\mathrm{~A}$ & G & & & 68 & 1 & $\vee$ & Conservative & \\
\hline 219 & 3 & $A$ & G & & & & & & & \\
\hline 222 & 3 & $\mathrm{~T}$ & C & & & & & & & \\
\hline 282 & 3 & $\mathrm{~T}$ & C & & & & & & & \\
\hline 342 & 3 & G & A & & & & & & & \\
\hline 366 & 3 & $A$ & G & & & & & & & \\
\hline 393 & 3 & $A$ & G & & & & & & & \\
\hline 441 & 3 & & & $\mathrm{~T}$ & $\mathrm{C}$ & & & & & I \\
\hline 474 & 3 & $\mathrm{~T}$ & C & & & & & & & \\
\hline 506 & 2 & $C$ & $\mathrm{~T}$ & & & 169 & $A$ & $\mathrm{~V}$ & Conservative & \\
\hline 516 & 3 & $\mathrm{~T}$ & C & & & & & & & \\
\hline 537 & 3 & $C$ & $\mathrm{~T}$ & & & & & & & \\
\hline 588 & 3 & $A$ & G & & & & & & & II \\
\hline 633 & 3 & $C$ & $\mathrm{~T}$ & & & & & & & \\
\hline 640 & 1 & $\mathrm{~T}$ & C & & & & & & & \\
\hline 645 & 3 & $C$ & $\mathrm{~T}$ & & & & & & & \\
\hline 663 & 3 & & & A & $\mathrm{G}$ & & & & & \\
\hline 684 & 3 & $\mathrm{~T}$ & C & & & & & & & \\
\hline 692 & 2 & G & A & & & 231 & $\mathrm{R}$ & $\mathrm{K}$ & Conservative & \\
\hline 714 & 3 & $\mathrm{~T}$ & C & & & & & & & \\
\hline 735 & 3 & & & G & $A$ & & & & & \\
\hline 759 & 3 & $A$ & G & & & & & & & \\
\hline 777 & 3 & $\mathrm{~T}$ & C & & & & & & & \\
\hline 849 & 3 & & & $\mathrm{~T}$ & $C$ & & & & & I \\
\hline 909 & 1 & $A$ & G & & & 303 & $\mathrm{~T}$ & $A$ & Nonconservative & III \\
\hline 912 & 3 & & & C & $\mathrm{T}$ & & & & & \\
\hline 1101 & 3 & $\mathrm{~T}$ & A & & & & & & & \\
\hline 1153 & 1 & $C$ & $\mathrm{~T}$ & & & & & & & \\
\hline 1172 & 2 & $\mathrm{G}$ & A & & & 391 & $\mathrm{R}$ & $\mathrm{K}$ & Conservative & \\
\hline 1269 & 3 & $\mathrm{G}$ & A & & & & & & & TM \\
\hline $128 \mid$ & 3 & $\mathrm{G}$ & A & & & & & & & \\
\hline 1302 & 3 & $C$ & G & & & & & & & \\
\hline 1317 & 3 & $\mathrm{G}$ & A & & & & & & & \\
\hline 1329 & 3 & & & A & $\mathrm{G}$ & & & & & \\
\hline 1380 & 3 & $C$ & $\mathrm{~T}$ & & & & & & & \\
\hline 1436 & 2 & $\mathrm{C}$ & $\mathrm{T}$ & & & 479 & $A$ & V & Conservative & \\
\hline 1466 & 2 & $\mathrm{~T}$ & $\mathrm{C}$ & & & 489 & V & $A$ & Conservative & \\
\hline
\end{tabular}

Domain I: I-156 nt $\left(1-52^{\text {aa }}\right) ; 397-573^{\text {nt }}(|33-19|$ aa $) ; 835-882^{\text {nt }}\left(279-294^{\text {aa }}\right)$

Domain II: 157-396 ${ }^{\text {nt }}\left(53-132^{\text {aa }}\right) ; 574-834^{\text {nt }}\left(192-278^{\text {aa }}\right)$

Domain III: 883-II $76^{\text {nt }}\left(295-392^{\text {aa }}\right)$

Domain TM: II77-1479nt (393-493aa)

nt:are indicated the nucleotide positions

aa::are indicated the amino acid positions 
(Group A) and another more closely related to the strain D3BR/BR8/2004 isolated in northern Brazil (Group B). Only the strain D3BR/RPAAF/2007 isolated in 2007 was more closely related to D3BR/RP1/2003 strain.

\section{Discussion}

The comparison of E protein gene sequences of DENV-3 revealed many variable sites; however, only 47 of them showed nucleotide substitutions that induced amino acid changes in a significant number of viruses (Additional file 5). Therefore, the E protein of DENV-3 showed 47 sites with variable amino acid residues, which were located mainly on the viral surface. Our molecular modeling analysis showed that all the amino acid substitutions do not interfere with the conformational structure of the E protein. These polymorphic amino acid residues could be involved in cell attachment, viral pathogenesis, and recognition by neutralizing antibodies $[12,13,32]$. Recently, it was shown that a panel of sera collected from DF and DHF patients 16-18 month after illness had different levels of neutralizing antibodies to different DENV-3 strains [33]. Those authors used in the neutralization tests isolates from Cuba and Puerto Rico, which showed amino acid substitutions at several of the 47 variable sites (Additional file 6). This suggests that those residues may be involved in neutralization differences, but further studies are necessary to confirm this hypothesis.

The phylogenetic analysis, based on $\mathrm{E}$ protein gene sequences, presented in this study showed that DENV-3 are distributed into four genotypes which is supported by complete mapping of this gene, and is in agreement with previous studies [25,34]. In addition, internal groups (lineages and sub-lineages) were observed within genotypes I, II and III. It was not possible to confirm internal subgrouping within the genotype IV due to the low number of sequences available in the GenBank. All amino acids that characterize a group (genotype, lineage, or sub-lineage) are located in the 47 variable sites of the $\mathrm{E}$ protein. Characteristic amino acid residues corresponding to the different DENV-3 genotypes, lineages, and sub-lineages are evenly distributed in the E protein, and most of them are exposed on the viral surface.

Recently, it has been reported the existence of a group of virus forming another genotype (genotype $\mathrm{V}$ ) within DENV-3 [29]. However, our phylogenetic and nucleotide/ amino acid substitution analysis suggest that those viruses of genotype $\mathrm{V}$ form a sub-group within the clade of genotype I and for this reason we have name this subgroup as lineage I. The phylogenetic trees generated in other studies using maximum likelihood and bayesian methods showed that the so-called genotype $\mathrm{V}$ is in the same clade of genotype I $[35,36]$. Therefore, we propose the mainte- nance of the classification of DENV-3 into four genotypes as previously suggested [25,34].

Other authors have also observed the existence of some of the intragenotypic groups described in this study. It has been observed that genotype I includes three groups of viruses: South Pacific, Philippines, and East Timor viruses [37]. South Pacific viruses are included in the sub-lineage I, while Philippines and East Timor are internal groups within our sub-lineage II of genotype I. It has also been suggested that genotype II includes two groups of viruses called: pre- and post-1992 [29]. These groups correspond to our lineages I and II of genotype II, respectively. The post-1992 viruses include groups A and B, which correspond to our sub-lineages I and II of lineage II. In addition, it has been suggested that isolates from Bangladesh form a distinct group within genotype II [38]. This group corresponds to our sub-lineage II of lineage I. Another study has also found three internal groups within genotype II: Malaysia, Bangladesh and Vietnam viruses [37]. These groups correspond to our sub-lineage I of lineage I, sub-lineage II of lineage I, and sub-lineage II of lineage II, respectively. The genotype III viruses have been classified into four groups: Latin America, East Africa and groups A and B from Sri Lanka viruses [39]. Our analysis showed a similar distribution of genotype III viruses; however, we found that Latin America viruses (lineage II) form two groups that we called sub-lineages I and II. These sub-lineages showed also internal monophyletic groups, which were omitted to simplify the classification. However, other authors have identified these internal groups within sub-lineages I and II [37,40-42].

All the DENV-3 isolated in Ribeirao Preto between 20062007 were grouped within the sub-lineage II/lineage II of genotype III. They were more closely related to viruses isolated in other cities than to those that were previously reported at Ribeirao Preto in 2003, suggesting that DENV3 is constantly moving within the country [43]. Brazil is a large tropical country with optimal conditions for the spread of dengue virus making difficult the control of the disease.

In summary, our results provide information about the most frequent amino acid changes in the $\mathrm{E}$ protein of DENV-3. These amino acids could be involved in cell attachment, virus pathogenesis, and recognition by neutralizing antibodies. However, further studies are needed to confirm these hypotheses. The phylogenetic relationship suggested the existence of only four genotypes of DENV-3. In addition, we observed internal groups within genotypes I, II and III. 


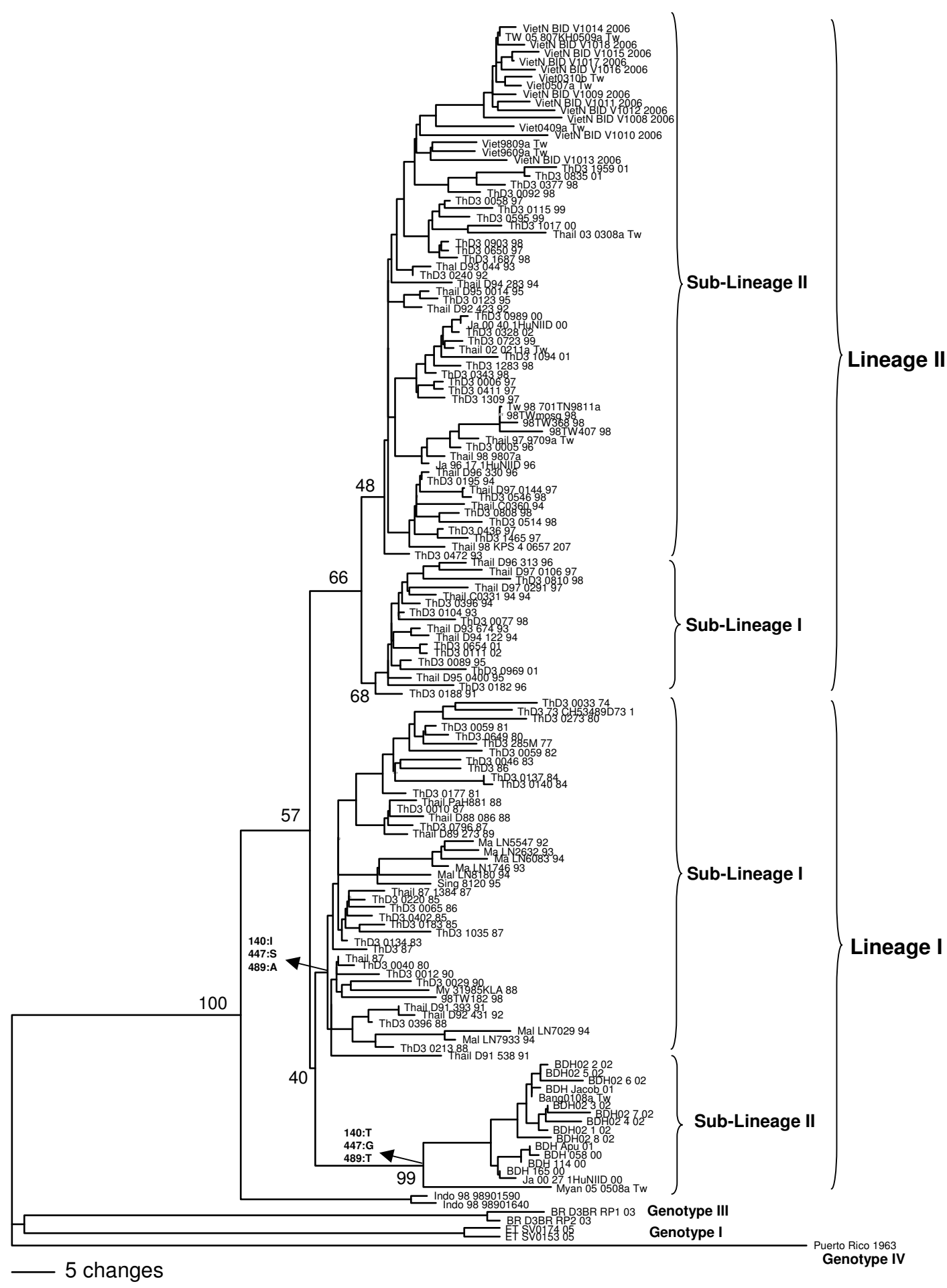

Figure 3

Genotype II phylogenetic tree constructed using the method of Neighbor-joining with I 000 bootstrap replications. Sequences of each genotype I, III and IV were used as outgroup. Branch lengths are proportional to percentage divergence. Tamura Nei $(\mathrm{TrN}+\mathrm{I}+\mathrm{G})$ nucleotide substitution model was used with a proportion of invariable sites (I) of $0.504 \mathrm{I}$ and gamma distribution (G) of I.3902. The lineage and sub-lineages are marked. Amino acids changes are indicated on the tree. Bootstrap support values are shown for key nodes only. 
Table 2: Nucleotide and amino acid substitutions in the informative sites of genotype II.

\begin{tabular}{|c|c|c|c|c|c|c|c|c|c|c|c|c|}
\hline \multicolumn{8}{|c|}{ Nucleotide } & \multicolumn{4}{|c|}{ Protein } & \multirow[t]{3}{*}{ Domains } \\
\hline & & \multicolumn{6}{|c|}{ Genotype II } & \multirow{3}{*}{ Position } & & & \multirow{4}{*}{ Type of amino acid Changes } & \\
\hline & & & & & I & Lin & e II & & & I & & \\
\hline \multicolumn{2}{|c|}{ Position } & \multicolumn{2}{|c|}{ Lineage } & \multicolumn{2}{|c|}{ Sub-Lineage } & \multicolumn{2}{|c|}{ Sub-Lineage } & & \multicolumn{2}{|c|}{ Sub-Lineage } & & \\
\hline Gene & Codon & $\mathbf{I}$ & II & $\mathbf{I}$ & II & $\mathbf{I}$ & II & Protein & $\mathbf{I}$ & II & & \\
\hline 54 & 3 & & & $\mathrm{~T}$ & $A$ & & & & & & & I \\
\hline 90 & 3 & & & & & $\mathrm{C}$ & $\mathrm{T}$ & & & & & \\
\hline 96 & 3 & & & & & $\mathrm{~T}$ & C & & & & & \\
\hline 273 & 3 & & & A & G & & & & & & & ॥ \\
\hline 351 & 3 & & & G & A & & & & & & & \\
\hline 419 & 2 & & & $\mathrm{~T}$ & C & & & 140 & 1 & $\mathrm{~T}$ & Nonconservative & I \\
\hline 549 & 3 & & & C & $\mathrm{T}$ & & & & & & & \\
\hline 525 & 3 & $A$ & $\mathrm{G}$ & & & & & & & & & \\
\hline 558 & 3 & & & G & C & & & & & & & \\
\hline 609 & 3 & $A$ & $\mathrm{C}$ & & & & & & & & & ॥ \\
\hline 708 & 3 & $\mathrm{G}$ & $A$ & & & & & & & & & \\
\hline 747 & 3 & & & $\mathrm{~T}$ & C & & & & & & & \\
\hline 834 & 3 & & & $\mathrm{~T}$ & C & & & & & & & \\
\hline 963 & 3 & & & G & A & & & & & & & III \\
\hline 1002 & 3 & $\mathrm{~T}$ & $\mathrm{C}$ & & & & & & & & & \\
\hline 1134 & 3 & & & G & C & & & & & & & \\
\hline 1176 & 3 & & & $\mathrm{~T}$ & A & & & & & & & \\
\hline 1188 & 3 & & & C & C & & & & & & & TM \\
\hline 1233 & 3 & & & A & $\mathrm{T}$ & & & & & & & \\
\hline 1339 & 1 & & & $\mathrm{~T}$ & G & & & 447 & $\mathrm{~S}$ & G & Nonconservative & \\
\hline 1436 & 2 & & & G & C & & & & & & & \\
\hline 1465 & 1 & & & A & $A$ & & & & & & & \\
\hline 1467 & 3 & & & $\mathrm{~T}$ & $\mathrm{~T}$ & & & 489 & A & $\mathrm{T}$ & Nonconservative & \\
\hline
\end{tabular}

Domain I: I-I56 $6^{\text {nt }}\left(I-52^{\text {aa }}\right) ; 397-573^{\text {nt }}(|33-19|$ aa $) ; 835-882^{\text {nt }}\left(279-294^{\text {aa }}\right)$

Domain II: 157-396 nt (53-132aa); 574-834t $\left(192-278^{\text {aa }}\right)$

Domain III: 883-II 176

Domain TM: II77-1479nt (393-493aa)

nt:are indicated the nucleotide positions

aa::are indicated the amino acid positions

\section{Methods}

\section{Virus and RNA purification}

Twenty DENV-3 strains isolated in C6/36 cells (passage number 2) from DF and DHF/DSS patients, between 2006-2007, in Ribeirao Preto city, Brazil, were included in this study. Viral RNA was purified from $140 \mu \mathrm{l}$ of culture fluid with the QIAamp Viral RNA kit (Qiagen, Germany), following manufacturer's recommendations.

\section{RT-PCR and sequencing}

The E protein gene of the samples were reverse-transcribed and amplified by polymerase chain reaction (RT-PCR), using consensus primers, as previously described [43]. The amplicons were purified from agarose gel using the QIAquick Gel Extraction Kit (Qiagen, USA), and directly sequenced in an ABI PRISM ${ }^{\circledR} 3100$ Genetic Analyzer (Applied Biosystems, USA). The sequences obtained in this study were submitted to the GenBank and registered with the following accession numbers: D3_BR/RP/1573/ 2006 (EU617019), D3_BR/RP/1604/2006 (EU617020), D3_BR/RP/1625/2006 (EU617021), D3_BR/RP/1651/ 2006 (EU617022), D3_BR/RP/2065/2006 (EU617023), D3_BR/RP/2131/2006 (EU617024), D3_BR/RP/2170/ 2006 (EU617025), D3_BR/RP/2198/2006 (EU617026), 
Table 3: Nucleotide and amino acid substitutions in the informative sites of genotype III.

\begin{tabular}{|c|c|c|c|c|c|c|c|c|}
\hline \multicolumn{8}{|c|}{ Nucleotide } & \multirow[t]{4}{*}{ Domains } \\
\hline & & & & & pe & & & \\
\hline & & & & & & & & \\
\hline \multicolumn{2}{|c|}{ Position } & \multicolumn{2}{|c|}{ Lineage } & \multicolumn{2}{|c|}{ Sub-Lineage } & \multicolumn{2}{|c|}{ Sub-Lineage } & \\
\hline Gene & Codon & $\mathbf{I}$ & II & I & II & $\mathbf{I}$ & II & \\
\hline 96 & 3 & & & & & C & $\mathrm{T}$ & I \\
\hline 117 & 3 & & & & & C & $A$ & \\
\hline 121 & I & C & $\mathrm{T}$ & & & & & \\
\hline 157 & 1 & & & & & C & $\mathrm{T}$ & \\
\hline 312 & 3 & $\mathrm{~T}$ & A & & & & & \\
\hline 423 & 3 & $\mathrm{~T}$ & $\mathrm{C}$ & & & & & \\
\hline 588 & 3 & $A$ & G & & & & & ॥ \\
\hline 633 & 3 & C & $\mathrm{T}$ & & & & & \\
\hline 672 & 3 & & & & & C & $\mathrm{T}$ & \\
\hline 784 & I & $\mathrm{C}$ & $\mathrm{T}$ & & & & & \\
\hline 825 & 3 & & & & & C & $\mathrm{T}$ & \\
\hline 1050 & 3 & $\mathrm{C}$ & $\mathrm{T}$ & & & & & II \\
\hline $113 \mid$ & 3 & & & & & A & G & \\
\hline 1170 & 3 & & & & & $\mathrm{C}$ & $\mathrm{T}$ & \\
\hline 1185 & 3 & & & G & $\mathrm{T}$ & & & TM \\
\hline 1314 & 3 & $\mathrm{~T}$ & $\mathrm{C}$ & & & & & \\
\hline 1356 & 3 & G & A & & & & & \\
\hline 1374 & 3 & $\mathrm{~T}$ & A & & & & & \\
\hline 1473 & 3 & $A$ & G & & & & & \\
\hline
\end{tabular}

Domain I: I-156 $6^{\text {nt }}\left(\mid-52^{\text {aa }}\right) ; 397-573^{\text {nt }}\left(|33-19|^{\text {aa }}\right) ; 835-882^{\text {nt }}\left(279-294^{\text {aa }}\right)$

Domain II: 157-396 ${ }^{\text {nt }}\left(53-132^{\text {aa }}\right)$; 574-834 $4^{\text {nt }}\left(192-278^{\text {aa }}\right)$

Domain III: 883-1 1 $76^{\text {nt }}\left(295-392^{\text {aa }}\right)$

Domain TM: II77-1479nt (393-493aa)

nt:are indicated the nucleotide positions

aa::are indicated the amino acid positions

D3_BR/RP/2404/2006 (EU617027)， D3_BR/RP/2591/ 2006 (EU617028), D3_BR/RP/2604/2006 (EU617029), D3_BR/RP/554/2006 (EU617030), D3_BR/RP/590/2006 (EU617031), D3_BR/RP/597/2006 (EU617032), D3_BR/ $\mathrm{RP} / \mathrm{AAF} / 2007$ (EU617033), D3_BR/RP/Val/2006 (EU617034), D3BR/RP/549/2006 (EU617035), D3BR/ $\mathrm{RP} / 1690 / 2006 \quad$ (EU617036)， D3BR/RP/2121/2006 (EU617037), D3BR/RP/2167/2006 (EU617038).

\section{Phylogenetic analysis of sequences}

The E protein gene sequences (1479 bp) obtained in this study were analyzed using the Vector NTI software (Informatix, USA) and then aligned with 427 sequences of DENV-3 retrieved from GenBank (Additional file 1) using the program CLUSTAL W software [44]. The alignment was edited with the BioEdit software v7.0.0 and MEGA 3.1 $[45,46]$. Aligned sequences were analyzed in the Model- test program to identify the best fit-model of nucleotide substitution for phylogenetic reconstruction; in all the analysis the Tamura and $\mathrm{Nei}(\operatorname{TrN}+\mathrm{I}+\mathrm{G})$ was the best model [47]. The best fit-model was selected under the hierarchical likelihood ratio test (hLTR). The phylogenetic relationships among strains were reconstructed by the neighbor-joining (NJ) and maximum parsimony (MP) methods using the PAUP 4.0B10 program [48].

\section{Structural analysis and comparisons}

In order to identify location of the amino acid residues in the $\mathrm{E}$ protein the putative E protein structure of different isolates were compared with the $\mathrm{E}$ protein structure of DENV-3 deposited in the Protein Data Bank (PDB) under the access code $1 \mathrm{UZG}[32]$. Analysis of the structures and construction of the illustrations were done using the graphical program Pymol [49]. 


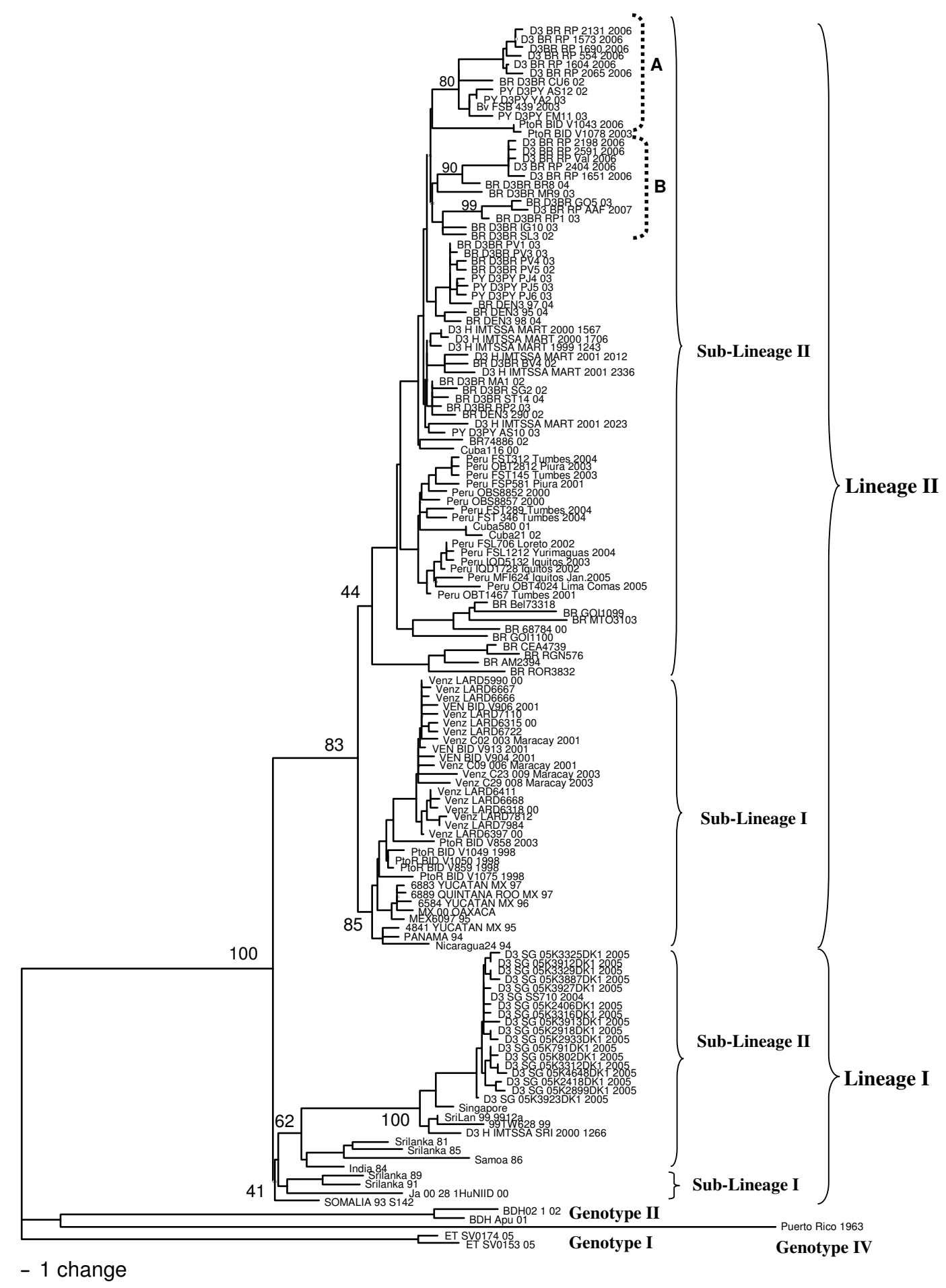

\section{Figure 4}

Genotype III phylogenetic tree constructed using the method of Neighbor-joining with I 000 bootstrap replications. Some viruses of each genotype I, II and IV were used as outgroup. Branch lengths are proportional to percentage divergence. Tamura Nei (TrN+G) nucleotide substitution model was used with gamma distribution (G) of 0.2796 . The Lineage and Sub-lineages are marked. Amino acids changes are indicated on the tree. Bootstrap support values are shown for key nodes only. 


\section{Competing interests}

The authors declare that they have no competing interests.

\section{Authors' contributions}

AAA, FTA, DJ, HLA, LCA, NAN, LTF and VHA conceived of the study, and participated in its design and coordination. All authors read and approved the final manuscript.

\section{Additional material}

\section{Additional file 1}

Database of the E protein gene sequences analyzed in this study. The file provides details on all the sequences including in this study.

Click here for file

[http://www.biomedcentral.com/content/supplementary/1743-

422X-6-113-S1.xls]

\section{Additional file 2}

Alignment of nucleotide and amino acid sequences of the E protein of the 361 strains of DENV-3. The file provides details on all the variable sites distributed in the E protein gene.

Click here for file

[http://www.biomedcentral.com/content/supplementary/1743422X-6-113-S2.xls]

\section{Additional file 3}

Nucleotide and amino acid substitutions in the 95 informative sites of the $E$ gene of DENV-3. The file provides details on nucleotide and amino acid substitutions in the informative sites of the E gene of DENV-3. Click here for file

[http://www.biomedcentral.com/content/supplementary/1743422X-6-113-S3.xls]

\section{Additional file 4}

A stereoscopic drawing of the tertiary structure of $E$ protein indicating the location of the amino acid residues. Domains I, II and III are colored in red, yellow and blue, respectively. The overlapping amino acids are in gray. A) Location of amino acids that characterize the genotypes. B) Location of amino acids that characterize the lineage I and II of the genotype I. C) Location of amino acids that characterize the groups within the lineage I of genotype II. D) Location of amino acids that characterize the groups within the lineage I of genotype III.

Click here for file

[http://www.biomedcentral.com/content/supplementary/1743422X-6-113-S4.ppt]

\section{Additional file 5}

Comparison of the E protein amino acid sequence of the 361 viruses. Details on the frequency of amino acids.

Click here for file

[http://www.biomedcentral.com/content/supplementary/1743422X-6-113-S5.xls]

\section{Additional file 6}

Comparison of $E$ the protein amino acid sequence of the Cuba strains and Puerto Rico. Sequence of isolates from Cuba and Puerto Rico, which showed differences of amino acids in several sites of the E protein. Click here for file

[http://www.biomedcentral.com/content/supplementary/1743422X-6-113-S6.xls]

\section{Acknowledgements}

This work received financial support from Fundação de Amparo a Pesquisa do Estado de São Paulo FAPESP), grants 05/04 I78-2. The authors are grateful to Prof. Maria. Cristina Nonato and Matheus P. Pinheiros by the help in structural analysis.

\section{References}

I. WHO: World Health Organization. Dengue and Dengue Haemorrhagic Fever. Fact Sheet No. I I 7. Geneva. 2002.

2. Dos Santos HWG, Poloni T, Souza KP, Muller VDM, Tremeschin F, Nali LC, Fantinatti LR, Amarilla AA, Castro HLA, Nunes MR, et al.: A simple one-step real-time RT-PCR for diagnosis of dengue virus infection. Journal of Medical Virology 2008, 80: I 426-| 433.

3. Henchal E, Putnak J: The dengue viruses. Clin Microbiol Rev 1990 3:376-396.

4. Mackenzie J, Gubler D, Petersen L: Emerging flaviviruses: the spread and resurgence of Japanese encephalitis, West Nile and dengue viruses. Nat Med 2004, 10:S98-109.

5. Anderson R, King A, Innis B: Correlation of $E$ protein binding with cell susceptibility to dengue 4 virus infection. J Gen Virol 1992, 73(Pt 8):2155-2159.

6. He R, Innis B, Nisalak A, Usawattanakul W, Wang S, Kalayanarooj S, Anderson R: Antibodies that block virus attachment to Vero cells are a major component of the human neutralizing antibody response against dengue virus type 2. J Med Virol 1995, 45:45I-46I.

7. Chen Y, Maguire T, Marks R: Demonstration of binding of dengue virus envelope protein to target cells. J Virol 1996, 70:8765-8772.

8. Lindenbach B, Rice C: Flaviviridae: the viruses and their replication. In Fields virology Volume I. Edited by: Knipe D, Howley P. Philadelphia: Lippincott Williams and Wilkins; 2001:99I-1042.

9. Beasley D, Aaskov J: Epitopes on the dengue I virus envelope protein recognized by neutralizing IgM monoclonal antibodies. Virology 200I, 279:447-458.

10. Crill W, Roehrig J: Monoclonal antibodies that bind to domain III of dengue virus $E$ glycoprotein are the most efficient blockers of virus adsorption to Vero cells. J Virol 200I, 75:7769-7773.

II. Modis Y, Ogata S, Clements D, Harrison S: Structure of the dengue virus envelope protein after membrane fusion. Nature 2004, 427:313-319.

12. Jennings A, Gibson C, Miller B, Mathews J, Mitchell C, Roehrig J, Wood D, Taffs F, Sil B, Whitby S: Analysis of a yellow fever virus isolated from a fatal case of vaccine-associated human encephalitis. J Infect Dis 1994, 169:5।2-5।8.

13. Rey F, Heinz F, Mandl C, Kunz C, Harrison S: The envelope glycoprotein from tick-borne encephalitis virus at $2 \mathrm{~A}$ resolution. Nature 1995, 375:29I-298.

14. Twiddy $\mathrm{S}$, Holmes $\mathrm{E}$, Rambaut $\mathrm{A}$ : Inferring the rate and timescale of dengue virus evolution. Mol Biol Evol 2003, 20: I22-129.

15. Russell P, McCown J: Comparison of dengue-2 and dengue-3 virus strains by neutralization tests and identification of a subtype of dengue-3. Am J Trop Med Hyg 1 972, 21:97-99.

16. Repik P, Dalrymple J, Brandt W, McCown J, Russell P: RNA fingerprinting as a method for distinguishing dengue $I$ virus strains. Am J Trop Med Hyg 1983, 32:577-589.

17. Trent D, Grant J, Rosen L, Monath T: Genetic variation among dengue 2 viruses of different geographic origin. Virology 1983 , I 28:27|-284.

18. Blok J: Genetic relationships of the dengue virus serotypes. J Gen Virol 1985, 66(Pt 6): 1323-1325.

19. Blok J, Henchal E, Gorman B: Comparison of dengue viruses and some other flaviviruses by cDNA-RNA hybridization analysis and detection of a close relationship between dengue virus serotype 2 and Edge Hill virus. J Gen Virol 1984, 65(Pt 12):2173-2I8I.

20. Kerschner J, Vorndam A, Monath T, Trent D: Genetic and epidemiological studies of dengue type 2 viruses by hybridization using synthetic deoxyoligonucleotides as probes. J Gen Virol 1986, 67(Pt I2):2645-266I.

21. Vorndam V, Nogueira R, Trent D: Restriction enzyme analysis of American region dengue viruses. Arch Virol 1994, 136:19|-196. 
22. Vorndam V, Kuno G, Rosado N: A PCR-restriction enzyme technique for determining dengue virus subgroups within serotypes. J Virol Methods 1994, 48:237-244.

23. Rico-Hesse R: Molecular evolution and distribution of dengue viruses type I and 2 in nature. Virology 1990, I74:479-493.

24. Lewis J, Chang G, Lanciotti R, Kinney R, Mayer L, Trent D: Phylogenetic relationships of dengue-2 viruses. Virology 1993 197:216-224.

25. Lanciotti R, Lewis J, Gubler D, Trent D: Molecular evolution and epidemiology of dengue-3 viruses. J Gen Virol 1994, 75(Pt I):65-75.

26. Goncalvez A, Escalante A, Pujol F, Ludert J, Tovar D, Salas R, Liprand $F$ : Diversity and evolution of the envelope gene of dengue virus type I. Virology 2002, 303:110-119.

27. Wang E, Ni H, Xu R, Barrett A, Watowich S, Gubler D, Weaver S: Evolutionary relationships of endemic/epidemic and sylvatic dengue viruses. J Virol 2000, 74:3227-3234

28. Twiddy S, Farrar J, Vinh Chau N, Wills B, Gould E, Gritsun T, Lloyd $\mathrm{G}$, Holmes E: Phylogenetic relationships and differential selection pressures among genotypes of dengue-2 virus. Virology 2002, 298:63-72.

29. Wittke V, Robb T, Thu H, Nisalak A, Nimmannitya S, Kalayanrooj S, Vaughn D, Endy T, Holmes E, Aaskov J: Extinction and rapid emergence of strains of dengue 3 virus during an interepidemic period. Virology 2002, 301: I48-156.

30. Lanciotti R, Gubler D, Trent D: Molecular evolution and phylogeny of dengue-4 viruses. J Gen Virol 1997, 78(Pt 9):2279-2284.

31. Worobey M, Rambaut A, Holmes E: Widespread intra-serotype recombination in natural populations of dengue virus. Proc Natl Acad Sci USA 1999, 96:7352-7357.

32. Modis $Y$, Ogata $S$, Clements $D$, Harrison S: Variable surface epitopes in the crystal structure of dengue virus type 3 envelope glycoprotein. J Virol 2005, 79:|223-|23|.

33. Alvarez M, Pavon-Oro A, Rodriguez-Roche R, Bernardo L, Morier L, Sanchez L, Alvarez A, Guzmán M: Neutralizing antibody response variation against dengue 3 strains. J Med Virol 2008, 80: $1783-1789$.

34. Chungue E, Deubel V, Cassar O, Laille M, Martin P: Molecular epidemiology of dengue 3 viruses and genetic relatedness among dengue 3 strains isolated from patients with mild or severe form of dengue fever in French Polynesia. J Gen Virol 1993, 74(Pt | 2):2765-2770.

35. Barrero $P$, Mistchenko A: Genetic analysis of dengue virus type 3 isolated in Buenos Aires, Argentina. Virus Res 2008, 135:83-88.

36. King C, Chao D, Chien L, Chang G, Lin T, Wu Y, Huang J: Comparative analysis of full genomic sequences among different genotypes of dengue virus type 3. Virol J 2008, 5:63.

37. Araújo J, Nogueira R, Schatzmayr H, Zanotto P, Bello G: Phylogeography and evolutionary history of dengue virus type 3. Infect Genet Evol 2009, 9:716-725

38. Podder G, Breiman R, Azim T, Thu H, Velathanthiri N, Mai IQ, Lowry $K$, Aaskov J: Origin of dengue type 3 viruses associated with the dengue outbreak in Dhaka, Bangladesh, in 2000 and 200I. Am J Trop Med Hyg 2006, 74:263-265.

39. Messer W, Gubler D, Harris E, Sivananthan K, de Silva A: Emergence and global spread of a dengue serotype 3 , subtype III virus. Emerg Infect Dis 2003, 9:800-809.

40. Fajardo A, Recarey R, de Mora D, D' Andrea L, Alvarez M, Regato M, Colina R, Khan B, Cristina J: Modeling gene sequence changes over time in type 3 dengue viruses from Ecuador. Virus Res 2009, I41:105-109.

41. de Mora D, Andrea L, Alvarez M, Regato M, Fajardo A, Recarey R, Colina R, Khan B, Cristina J: Evidence of diversification of dengue virus type 3 genotype III in the South American region. Arch Virol 2009, I 54:699-707.

42. Kochel T, Aguilar P, Felices V, Comach G, Cruz C, Alava A, Vargas J, Olson J, Blair P: Molecular epidemiology of dengue virus type 3 in Northern South America: 2000 - 2005. Infect Genet Evol 2008, 8:682-688.

43. Aquino $V$, Anatriello $E$, Gonçalves $P$, DA Silva E, Vasconcelos P, Vieira D. Batista W, Bobadilla M, Vazquez C, Moran M, Figueiredo L: Molecular epidemiology of dengue type 3 virus in Brazil and Paraguay, 2002-2004. Am J Trop Med Hyg 2006, 75:710-7I5.

44. Thompson J, Gibson T, Plewniak F, Jeanmougin F, Higgins D: The CLUSTAL_X windows interface: flexible strategies for mul- tiple sequence alignment aided by quality analysis tools. Nucleic Acids Res 1997, 25:4876-4882.

45. Hall T: : BioEdit: a user-friendly biological sequence alignment editor and analysis program for Windows 95/98/NT. Nucl Acids Symp Ser 1999, 41:95-98.

46. Kumar S, Tamura K, Nei M: MEGA3: Integrated software for Molecular Evolutionary Genetics Analysis and sequence alignment. Brief Bioinform 2004, 5:150-163.

47. Posada D: ModelTest Server: a web-based tool for the statistical selection of models of nucleotide substitution online. Nucleic Acids Res 2006, 34:W700-703.

48. Swofford D: PAUP*: phylogenetic analysis using parsimony (*and other methods). In Version 4.0b/0a Sunderland, Mass: Sinauer Associates; 1998.

49. Delano W: The PyMOL Molecular Graphics System. 2002 [http://www.pymol.org]. San Carlos, CA, USA
Publish with Biomed Central and every scientist can read your work free of charge

"BioMed Central will be the most significant development for disseminating the results of biomedical research in our lifetime. "

Sir Paul Nurse, Cancer Research UK

Your research papers will be:

- available free of charge to the entire biomedical community

- peer reviewed and published immediately upon acceptance

- cited in PubMed and archived on PubMed Central

- yours - you keep the copyright 